En admettant que les masses des compagnons se trouvaient dans le plan de l'orbite de $A$, on peut caiculer leurs positions par rapport à $A$ à l'aide des formules employées pour les queues des comètes, et on obtient ainsi pour E, par exemple:

$$
\begin{aligned}
& \text { août } 5.25 \\
& \text { oct. 23.42 }
\end{aligned} \quad A=\begin{aligned}
& 0.0076 \\
& 0.0170
\end{aligned} \quad \varphi=\begin{aligned}
& 319^{\circ} .5 \\
& 207.8
\end{aligned}
$$

D'après les éléments respectifs on a pour ces dates:

$$
\begin{aligned}
& A \quad E \\
& \text { août } 5.25
\end{aligned}
$$

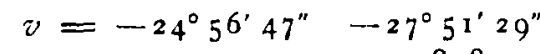

$$
\begin{aligned}
& \log r=0.3024104 \quad 0.3038484 \\
& \text { oct. } 23.4^{2} \quad z^{\prime}=+9^{\circ} 20^{\circ} 5^{\prime \prime}+6^{\circ} 29^{\prime} 54^{\prime \prime} \\
& \log r=0.2911104 \quad 0.2882955
\end{aligned}
$$

Avec ces données on calcule pour $E$ :

$$
\begin{aligned}
& \text { août } 5.25 \\
& \text { oct. } 23.42
\end{aligned} \quad \Delta=\begin{aligned}
& 0.0077 \\
& 0.0139
\end{aligned} \quad \varphi=\begin{aligned}
& 33^{1.2} \\
& 204.1
\end{aligned}
$$

Ces valeurs s'accordent avec les valeurs tirées de l'observation dans les limites des erreurs des estinations.
Il est très intéressant que les éléments de $C$ et de $E$ indiquent presque le même point pour la séparation des masses de la comète génératrice.

Probablement cette séparation est produite par l'attraction excessivement forte de Jupiter (Chandler, Astron. Journal, No. 205).

Si l'on voulait l'attribuer à l'action éruptive de la comète, on trouverait pour la masse $C$ le choc $j=+0.0014$ et dirigé vers le Soleil, suivant le rayon vecteur, et pour la masse $E j=-0.0147$, c'est à dire le chor dirigé à l'opposite du Soleil, suivant le rayon vecteur prolongé. -

$$
\text { Note. }
$$

La petite queue de la comète r 889 I observée par M. Barnard le 3 juin 1889 , a paru anomale par l'effet de la perspective.

En calculant sa position réelle par rapport au noyau nous avons trouvé $\Delta=0.0701$ et $\varphi=57.8$ en arrière du rayon vecteur prolongé. Donc c'est une queue normale et du III type, car il est facile de trouver pour lui la valeur de $\mathbf{I}-\boldsymbol{\mu}=0.04$. Il ne faut pas perdre de vue la petitesse de cette queue et l'insuffisance d'une seule estimation pour le calcul tant soit peu exact de la force répulsive.

1889 décembre 17 .

Th. Bredichin.

\title{
Some formulae for the correction of meridian transit observations
}

which have been reduced with erroneous values of the insrumental constants.

\section{By Milton Updegraff, Assistant Astronomer.}

It sometimes happens, after the complete reduction of a series of transit observations, that the necessity appears of adopting different values of one or more of the instrumental constants, $a, b, c$ or $n$. This is especially liable to occur in case of the collimation constant $c$ through change in the wire intervals of a spider-line reticule or in case of the constants $n$ and $a$ through the adoption of new places for the circumpolar stars.

The labor of re-reduction may be avoided by the use of formulae for computing the necessary corrections to the erroneous Right Ascensions which were derived from the erroneous values of the constants first adopted. I have derived two sets of formulae for this purpose, the first to be used when the observations have been reduced by Bessel's formula and the second when the observations have been reduced by Mayer's formula for the reduction of observations in Right Ascension.

\section{For Bessel's Formula.}

When a night's work in Right Ascension has been Then we have, from Bessel's formula (see Chauvenet's reduced with a wrong value of the collimation constant, let Spherical and Practical Astronomy Vol. II Page I43), for $c^{\prime}$ be this erroneous collimation and $c$ the correct one. any star observed at declination $\delta$

$$
\begin{aligned}
& \alpha=T+(\Delta T+m)+n \tan \delta+c \sec \delta \\
& \iota^{\prime}=T+\left(\Delta T^{\prime}+m^{\prime}\right)+n^{\prime} \tan \delta+c^{\prime} \sec \delta
\end{aligned}
$$

$\alpha, A T+m$ and $n$ corresponding to the true value of the collimation, $c$, and $\alpha^{\prime}, A T^{\prime}+m^{\prime}$ and $n^{\prime}$ to the erroneous value $c^{\prime}$. Subtracting Eq. (2) from Eq. (I)

$$
\alpha-\alpha^{\prime}=(\Delta T+m)-\left(\Delta T^{\prime}+m^{\prime}\right)+\left(n-n^{\prime}\right) \tan \delta+\left(c-c^{\prime}\right) \sec \delta
$$

For a time star at declination $\delta_{1}, \quad \Delta T+m=\alpha_{1}-T_{1}-c \sec \delta_{1}-n \tan \delta_{1}$

$$
\begin{gathered}
\Delta T^{\prime}+m^{\prime}=a_{1}-T_{1}-c^{\prime} \sec d_{1}-n^{\prime} \tan \delta_{1} \\
(\Delta T+m)-\left(\Delta T^{\prime}+m^{\prime}\right)=-\left(c-c^{\prime}\right) \sec d_{1}-\left(n-n^{\prime}\right) \tan \delta_{1}
\end{gathered}
$$


From equations (3) and (4)

$$
a-a^{\prime}=\left(c-c^{\prime}\right)\left(\sec \delta-\sec \delta_{1}\right)+\left(n-n^{\prime}\right)\left(\tan \delta-\tan \delta_{1}\right)
$$

For a pair of circumpolar stars U.C. and L. C. whose declinations are $\delta_{2}$ and $180^{\circ}-\delta_{3}$ (L. C.) and which have been observed for determining the constant $n$, we have for collimation $c$,

$$
\begin{aligned}
& n \tan \delta_{2}=\alpha_{2}-T_{2}-(\Delta T+m)-c \sec \delta_{2} \\
& n \tan \left(180^{\circ}-\delta_{3}\right)=a_{3}-T_{3}-(A T+m)-c \sec \left(180^{\circ}-\delta_{3}\right) \\
& n\left(\tan \delta_{2}+\tan \delta_{3}\right)=\alpha_{2}-\alpha_{3}-T_{2}+T_{3}-c\left(\sec \delta_{2}+\sec \delta_{3}\right) \\
& n=\frac{c_{2}-\alpha_{3}-T_{2}+T_{3}}{\tan \delta_{2}+\tan \delta_{3}}-c \frac{\sec d_{2}+\sec \delta_{3}}{\tan \delta_{3}+\tan \delta_{3}} . \\
& n^{\prime}=\frac{\alpha_{2}-\alpha_{3}-T_{2}+T_{3}}{\tan \delta_{2}+\tan \delta_{3}}-c^{\prime} \cdot \frac{\sec \delta_{2}+\sec \delta_{3}}{\tan \delta_{2}+\tan \delta_{3}} \quad \text { subtracting, } \\
& n-n^{\prime}=-\left(c-c^{\prime}\right) \cdot \frac{\sec \delta_{2}+\sec \delta_{3}}{\tan \delta_{2}^{-}+\tan \delta_{9}}
\end{aligned}
$$

For collimation $c^{\prime}$

From equations (5) and (6)

$$
\alpha \cdot-a^{\prime}=\left(c-c^{\prime}\right)\left(\sec \delta-\sec \delta_{1}\right)-\left(c-c^{\prime}\right) \frac{\sec \delta_{2}+\sec \delta_{3}}{\tan \frac{\delta_{2}}{\delta_{2}}+\tan \overline{\delta_{3}}}\left(\tan \delta-\tan \delta_{1}\right)
$$

Equation (7) gives the correction $r-\alpha^{\prime}$ for a star at polar stars at declinations $\delta_{2}$ (U.C.) and $180^{\circ}-\delta_{3}$ (L.C.). declination $\delta$ referred to a time star at declination $\delta_{1}$, the constant $n$ having been determined from a pair of circum-

When there are $p$ time stars and $q$ pairs of circumpolars, equation (7) assumes this form

$$
\alpha-\epsilon^{\prime}=\left(c-c^{\prime}\right)\left(\sec \delta-\frac{\tan \delta}{q} \sum \frac{\sec \delta_{u t}+\sec \delta_{l}}{\tan \delta_{u}+\tan \delta_{l}}\right)-c-c^{\prime}\left(\Sigma \sec \delta_{t}-\frac{\Sigma \tan \delta_{t}}{q} \sum \frac{\sec \delta_{u}+\sec \delta_{l}}{\tan \delta_{u}+\tan \delta_{l}}\right)
$$

in which $\Sigma \sec \delta_{t}$ and $\Sigma \tan \delta_{t}$ are the sums of the secants and tangents of the declinations of the $p$ time stars and $\sum \frac{\sec \delta_{u}+\sec \delta_{l}}{\tan \delta_{u t}+\tan \delta_{l}}$ is the sum of the secants of the circum $\sum \frac{\sec d_{u}+\sec d_{l}}{\tan \delta_{u}+\tan d_{l}}$ $q \sum \overline{\tan \delta_{u}}+\tan \delta_{l}$ may be taken equal to +1 and when polars U. C. and L. C. divided by the sum of their tangents. When the declinations of the circumpolar stars are all plus,

$$
a-a^{\prime}=\left(c-c^{\prime}\right)(\sec \delta \mp \tan \delta)-\frac{c-c^{\prime}}{p} \sum\left(\sec \delta_{t} \mp \tan \delta_{t}\right)
$$

the ambiguous signs to be taken minus when the circum- For a time star at declination $\delta_{1}$ polars are north stars and plus when the circumpolars are south stars.

In case the error of the collimation $c-c^{\prime}$ is large enough or the distribution of the time stars such, that the rate of variation of $\Delta T+i n$ is sensibly affected, the time stars must be divided into groups and a variable value of $\frac{c-c^{\prime}}{p} \sum\left(\sec \delta_{t} \mp \tan \delta_{t}\right)$ used.

When a wrong value of $n$ has been employed let $n^{\prime}$ be the erroneous value and $n$ the correct value. Then for any star

$$
\begin{gathered}
a=T+(\Delta T+m)+n \tan \delta+c \sec \delta \\
a^{\prime}=T+\left(\Delta T^{\prime}+m^{\prime}\right)+n^{\prime} \tan \delta+c \sec \delta \\
a-a^{\prime}=(\Delta T+m)-\left(A T^{\prime}+m^{\prime}\right)+\left(n-n^{\prime}\right) \tan \delta
\end{gathered}
$$

$$
\begin{gathered}
\Delta T+m=a_{1}-T_{1}-c \sec \delta_{1}-n \tan \delta_{1} \\
\Delta T^{\prime}+m^{\prime}=a_{1}-T_{1}-c \sec \delta_{1}-n^{\prime} \tan \delta_{1} \\
(\Delta T+m)-\left(\Delta T^{\prime}+m^{\prime}\right)=-\left(n-n^{\prime}\right) \tan \delta_{1} \\
a-a^{\prime}=-\left(n-n^{\prime}\right) \tan \delta_{1}+\left(n-n^{\prime}\right) \tan \delta \\
a-a^{\prime}=\left(n-n^{\prime}\right)\left(\tan \delta-\tan \delta_{1}\right)
\end{gathered}
$$

In case of $p$ time stars, using the same notation as before, we have

$$
a-a^{\prime}=\left(n-n^{\prime}\right)\left(\tan \delta-\frac{\mathrm{I}}{p} \sum \tan \delta_{t}\right)
$$

\section{For Mayer's Formula.}

$A, B$ and $C$ being the transit factors whose values depend on the latitude of the place of observation and the declination of the star, we have from Mayer's formula (Chauvenet Vol. II Page 145) for the two values of the collimation $c$ and $c^{\prime}$ 


$$
\begin{aligned}
a & =T+\Delta T+a A+b B+c C \\
a^{\prime} & =T+\Delta T^{\prime}+a^{\prime} A+b B+c^{\prime} C \\
u-a^{\prime} & =\Delta T-\Delta T^{\prime}+\left(a-a^{\prime}\right) A+\left(c-c^{\prime}\right) C
\end{aligned}
$$

For a time star at declination $\delta_{1}$

$$
\begin{aligned}
\Delta T & =\alpha_{1}-T_{1}-a A_{1}-b B_{1}-c C_{1} \\
\Delta T^{\prime} & =\alpha_{1}-T_{1}-a^{\prime} A_{1}-b B_{1}-c^{\prime} C_{1} \\
\Delta T-\Delta T^{\prime} & =-\left(a-a^{\prime}\right) A_{1}-\left(c-c^{\prime}\right) C_{1}
\end{aligned}
$$

From equations (3) and (4)

$$
\alpha-a^{\prime}=\left(a-a^{\prime}\right)\left(A-A_{1}\right)+\left(c-c^{\prime}\right)\left(C-C_{1}\right)
$$

For any two stars at declinations $\delta_{2}$ and $\delta_{3}$ used for determining the azimuth constant $a$ we have for collimation $c$

From equations (5) and (6)

$$
\begin{aligned}
-A_{2} a & =T_{2}+\Delta T-a_{2}+b B_{2}+c C_{2} \\
-A_{3} a & =T_{3}+\Delta T-\alpha_{3}+b B_{3}+c C_{3} \\
-a\left(A_{2}-A_{3}\right) & =T_{2}-T_{3}-\alpha_{2}+\alpha_{3}+b\left(B_{2}-B_{3}\right)+c\left(C_{2}-C_{3}\right) .
\end{aligned}
$$

And for collimation $c^{\prime}$

$$
\begin{aligned}
-a^{\prime}\left(A_{2}-A_{3}\right) & =T_{2}-T_{3}-a_{2}+\alpha_{3}+b\left(B_{2}-B_{3}\right)+c^{\prime}\left(C_{2}-C_{3}\right) \\
-\left(a-a^{\prime}\right)\left(A_{2}-A_{3}\right) & =\left(c-c^{\prime}\right)\left(C_{2}-C_{3}\right) . \\
a-a^{\prime} & =-\left(c-c^{\prime}\right) \frac{C_{2}-C_{3}}{A_{2}-\bar{A}_{3}} .
\end{aligned}
$$

$$
a-\alpha^{\prime}=\left(c-c^{\prime}\right)\left(C-C_{1}\right)-\left(c-c^{\prime}\right)\left(A-A_{1}\right) \frac{C_{2}-C_{3}}{A_{2}-A_{3}}
$$

When there are $p$ time stars and $q$ pairs of circumpolars, using the same notation as before we have

$$
\begin{aligned}
& a-a^{\prime}=\left(c-c^{\prime}\right)\left(C-\frac{\Sigma C_{t}}{p}\right)-\left(c-c^{\prime}\right)\left(A-\frac{\Sigma A_{t}}{p}\right) \frac{I}{q} \sum \frac{C_{2}-C_{3}}{A_{2}-A_{3}} \text { or } \\
& \alpha-a^{\prime}=\left(c-c^{\prime}\right)\left(C-\frac{A}{q} \sum \frac{C_{2}-C_{3}}{\bar{A}_{2}-A_{3}}\right)-\frac{c-c^{\prime}}{p}\left(\sum C_{t}-\frac{\Sigma A_{t}}{q} \sum \frac{C_{2}-C_{3}}{A_{2}^{-}-\bar{A}_{3}}\right)
\end{aligned}
$$

On substituting the known transit factors of the fundamental stars and the values of $p$ and $q$ for any one night's work formula (III) assumes the form

$$
\alpha-\alpha^{\prime}=\left(c-c^{\prime}\right)\left(C-A K_{1}\right)+K_{2}
$$

$K_{1}$ and $K_{2}$ being constant quantities.

By exactly the same process we arrive at the following expression for $a-a^{\prime}$ due to error of the level constant $b$

$$
a-a^{\prime}=\left(b-b^{\prime}\right)\left(B-B^{\prime}-\left(A-A^{\prime}\right) \cdot \frac{B_{2}-B_{3}}{A_{2}-A_{3}}\right)
$$

Now $A=-\frac{\sin (\varphi-\delta)}{\cos \delta}$ and $B=\frac{\cos (\varphi-\delta)}{\cos \delta}$. Substituting these values of $A$ and $B$ and also the similar expressions for $A_{1}, B_{1}, A_{2}, B_{2}, A_{3}$ and $B_{3}$ we find, after reducing to the simplest form, that

$$
\alpha-a^{\prime}=0 \text {. }
$$

Therefore an error in the adopted level constant does not directly affect the observed Right Ascensions. But it

Observatorio Nacional, Cordoba, Argentine Republic, 1889 Sept. 28. does affect the $\Delta T$ and therefore the determination of the clock rate.

When a wrong azimuth has been used let $a$ be the correct value and $a^{\prime}$ the erroneous value.

$$
\begin{aligned}
a & =T+\Delta T+a A+b B+c C \\
a^{\prime} & =T+\Delta T^{\prime}+\alpha^{\prime} A+b B+c C \\
\alpha-a^{\prime} & =\Delta T-\Delta T^{\prime}+\left(a-a^{\prime}\right) A
\end{aligned}
$$

For a time star at declination $\delta_{1}$

$$
\begin{aligned}
& \Delta T=a_{1}-T_{1}-a A_{1}-b B_{1}-c C_{1} \\
& \Delta T^{\prime}=a_{1}-T_{1}-a^{\prime} A_{1}-b B_{1}-c C_{1} \\
& \Delta T-\Delta T^{\prime}=-\left(a-a^{\prime}\right) A_{1} \\
& a-a^{\prime}=\left(A-A_{1}\right)\left(a-a^{\prime}\right)
\end{aligned}
$$

and when there are $p$ time stars

$$
u-a^{\prime}=\left(a-a^{\prime}\right)\left(A-\frac{\Sigma}{p} A_{t}\right) .
$$

